\title{
Latrine ownership as a protective factor in inflammatory trachoma in Egypt
}

Paul Courtright, John Sheppard, Sandra Lane, Aly Sadek, Julius Schachter, Chandler R Dawson

\begin{abstract}
We investigated the association between inflammatory trachoma in children aged 1-5 and environmental and sociodemographic risk factors in a rural Nile Delta hamlet. Inflammatory trachoma clustered in households, emphasising the child-to-child nature of transmission in the hamlet. Multiple logistic regression analysis revealed three factors predicting inflammatory trachoma in children: the absence of a latrine in the household, school-age siblings with inflammatory trachoma, and additional same-age siblings (with or without disease) in the household. In the Egyptian setting the presence of pit latrines in all houses, even when full and unscreened, might result in a reduction in trachoma prevalence in this population from the current $49 \%$ to $35 \%$. The construction of pit latrines may offer the simplest and most acceptable environmental method for reducing trachoma in this trachoma endemic area.
\end{abstract}

Much progress has been made recently in elucidating the factors, some of which may be cultural or site specific, influencing the intensity of inflammatory trachoma in children. However, all the factors associated with inflammatory trachoma which might be amenable to intervention have not been established. As with other communicable diseases, trachoma is intricately bound up with environmental, demographic, and social factors. Poor hygiene (including face washing) and low socioeconomic status are most commonly cited as risk factors for the presence of inflammatory trachoma. ${ }^{1-18}$ Researchers have identified other risk factors for trachoma inflammation including fly density, ${ }^{19-20}$ geographic and climatic characteristics, ${ }^{21} 22$ crowding and family size, ${ }^{2351323-25}$ and occupation and education of household head. ${ }^{235613}$ There is considerable intercorrelation between these predictors of trachoma inflammation, and yet in only three of these studies ${ }^{1818}$ were the predictors assessed independently. Furthermore, the contribution of household clustering of trachoma to the results was not examined.

The purpose of this study was to define those environmental characteristics that were independently associated with inflammatory trachoma in the rural Nile Delta of Egypt and to suggest public health measures to reduce the prevalence of trachoma.
Materials and methods

All residents of an Egyptian Nile Delta hamlet, Kafr (population 1107), were examined with a portable slit-lamp for inflammatory and cicatricial trachoma in January 1987. This area has been the focus of considerable population based research into blindness and trachoma because trachoma remains a serious public health problem. ${ }^{26-29}$

The clinical findings were recorded by the detailed WHO grading system for trachoma. ${ }^{30}$ For the purpose of this paper inflammatory trachoma was recorded as present if the inflammatory disease was of moderate to severe intensity, and absent if there was mild to insignificant conjunctival inflammation. Trachoma intensity was determined by the disease in the worse eye. The analysis focuses on children aged 1-5 years, because this age group accounts for the bulk of the inflammatory trachoma in this and other trachoma endemic populations. Furthermore, the environment of children aged 1-5 is closely linked to the household, the focus of this risk factor investigation, while children older than 5 have substantial contact outside the

Table 1 Environmental and socio-demographic factors investigated in Kafr, Egypt, 1987

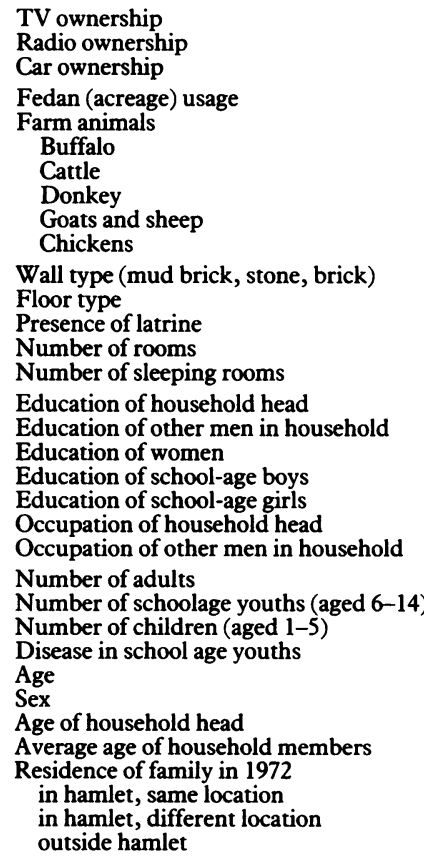


household. Children less than 1 year old were excluded from the data set owing to the difficulty of examining infants and the low prevalence of clinical disease in this age group.

A household was defined as the aggregate of persons who, at the time of the survey, were sleeping in the same house. Thus households generally consisted of extended families and, in rare cases, persons not related by kinship to the head of the household.

Data on environmental and socio-demographic factors, shown in Table 1, were collected on both the household (cluster) level and individual level by interview and observation. Constructed variables included number of persons per sleeping room and number of large farm animals per person per room. The former is a measure of the potential for transmission of trachoma, and the latter (animal are kept in the house) is a measure of socioeconomic status and exposure to animal wastes.

We assessed the interrelation between risk factors and their effect on trachoma status by multiple logistic regression analysis using EGRET, controlling for other confounding variables and the contribution of household clustering in the results. ${ }^{31}$ A subset of variables repesenting potential predictors of trachoma by univariate analysis $\left(\chi^{2}\right.$ exceeding $2 \cdot 4$, or $\left.p<0 \cdot 11\right)$ were selected for inclusion in the logistic model. Variables were included in the regression model on a step-wise fashion to construct an estimate utilising information from the other factors to estimate the risk in each one, giving rise to the odds ratio as a measure of association. Although not presented here, the role of household clustering on the results was assessed to ensure the validity of the results. ${ }^{32}$

\section{Results}

We examined 225 of 232 children aged 1-5 (response rate $=97 \%$ ) from 96 households. The prevalence of inflammatory trachoma (severe and moderate intensity) in the study population was $49 \%$. The age specific prevalence of active inflammation peaked at $60 \%$ among children 3 years old, and boys had a slightly higher prevalence of active trachoma than did girls (Table 2).

There was a strong tendency for trachoma to cluster in households. In 13 of 66 households (20\%) with two or more children there were no active trachoma cases, while in 21 of the remaining households (32\%) all children in the target age group had active trachoma. Household clustering of trachoma, while significant in nature, did not change the relative significance of the findings.

There is no running water or electricity in the hamlet, and only two vehicles are owned by residents. Homes are tightly packed in a halfsquare mile $\left(1.3 \mathrm{~km}^{2}\right)$ area, and there are large piles of manure (human and animal) throughout the hamlet. All residents are Muslim and most are long-term inhabitants. Televisions and radios are operated on automobile batteries. Most families $(53 \%)$ reported that they farmed two fedan - about 1.5 acre $(0.6 \mathrm{ha})$. Twenty-eight households (22\%) did not engage in farming.
The majority of houses were constructed from packed mud, but newer houses have been constructed from either stone or brick. Just under half of the houses had a pit latrine; the rest had no latrine. The median number of rooms per household was four, with a range of one to 10 . Young children slept together with their parents in one large bed, and older siblings, particularly boys, often slept with grandparents in a separate room. Only $21 \%$ of households did not own a donkey, while $13 \%$ owned two or more. Many men worked in a textile mill $10 \mathrm{~km}$ distant. Only $22 \%$ of girls of school age attended school.

Univariate analysis of data according to the trachoma status of the household is given in Table 3. Utilising multiple logistic regression analysis we concluded that the number of children in the household, the absence of a latrine in the household, and disease in schoolage siblings were the most important factors associated with trachoma intensity in children (Table 4). Other variables failed to explain

Table 2 Prevalence of inflammatory trachoma by age of children in Kafr, Egypt, 1987

\begin{tabular}{lcc}
\hline Age (years) & Severe/moderate trachoma $(\%)$ & No trachoma $(\%)$ \\
\hline 1 & $16(42 \%)$ & $22(58 \%)$ \\
2 & $23(50 \%)$ & $23(50 \%)$ \\
3 & $29(60 \%)$ & $19(40 \%)$ \\
4 & $23(50 \%)$ & $23(50 \%)$ \\
5 & $20(43 \%)$ & $27(57 \%)$ \\
Total & $111(49 \%)$ & $114(51 \%)$ \\
\hline
\end{tabular}

Table 3 Distribution of household characteristics

\begin{tabular}{|c|c|c|}
\hline Characteristic & $\begin{array}{l}\text { Trachomatous } \\
\text { household }\end{array}$ & $\begin{array}{l}\text { Non-trachomatous } \\
\text { household }\end{array}$ \\
\hline \multicolumn{3}{|l|}{ TV/radio ownership } \\
\hline Both owned & $19(20 \%)$ & $21(22 \%)$ \\
\hline Neither/either & $36(38 \%)$ & $18(19 \%)$ \\
\hline People per fedan & 5.98 & 4.82 \\
\hline Number of animals & 3.68 & $2 \cdot 67$ \\
\hline Animals per room & 0.80 & 0.57 \\
\hline \multicolumn{3}{|l|}{ Latrine in house } \\
\hline Absent & $37(39 \%)$ & $13(14 \%)$ \\
\hline Present & $18(19 \%)$ & $26(27 \%)$ \\
\hline \multirow{2}{*}{\multicolumn{3}{|c|}{$\begin{array}{l}\text { Rooms per person } \\
\text { Occupation of males }\end{array}$}} \\
\hline & & \\
\hline $\begin{array}{l}\text { Farmer/manual labor } \\
\text { Factory/professional }\end{array}$ & $\begin{array}{l}40(43 \%) \\
15(16 \%)\end{array}$ & $25(26 \%)$ \\
\hline \multicolumn{3}{|c|}{ Trachoma in school age siblings } \\
\hline Present & $30(32 \%)$ & $9(10 \%)$ \\
\hline & $25(26 \%)$ & $30(32 \%)$ \\
\hline Number of children 1-5 & 2.85 & $2 \cdot 00$ \\
\hline Number of youths 6-14 & 2.69 & 1.92 \\
\hline Number of adults $15+$ & $5 \cdot 60$ & $4 \cdot 33$ \\
\hline
\end{tabular}

^Trachomatous household defined as household with at least one child (age 1-5) with moderate-severe inflammatory trachoma. 1 Fedan $=0.3$ ha.

Table 4 Predictors of disease: odds ratio (and confidence intervals) in Kafr, Egypt, 1987

\begin{tabular}{ll}
\hline Parameter & Odds ratio $(95 \% C I) p$ \\
\hline Disease in school-age siblings & $4 \cdot 4(2 \cdot 0,10 \cdot 8)<0 \cdot 001$ \\
Absence of latrine & $3 \cdot 3(1 \cdot 6,6 \cdot 2)<0 \cdot 001$ \\
Number of children & $1 \cdot 3(1 \cdot 2,1 \cdot 5) 0 \cdot 01$ \\
\hline
\end{tabular}

Table 5 Proportion of children aged 1-5 by size of household

\begin{tabular}{ll}
\hline Household size $^{\star}$ & $\begin{array}{l}\text { Children as percentage of total } \\
\text { household members }\end{array}$ \\
\hline $1-4$ members & $15 \%$ \\
$5-8$ members & $20 \%$ \\
$9-12$ members & $20 \%$ \\
$13+$ members & $24 \%$ \\
\hline
\end{tabular}

Test for trend: $F=14 \cdot 0, p<0 \cdot 001$.

${ }^{\star}$ Number of inhabitants sleeping in the same household. 
independently the variation in trachoma intensity in this population. The presence of a latrine was not associated with various measures of socioeconomic status, including occupation and education of household head, number of large farm animals, and acreage farmed by the household.

The number of children (aged 1-5) in households ranges from 0 to 12 with a median of 2 . Households with numerous members had proportionately more children than households with few members (Table 5). The log odds of disease in a child increased by 0.22 with each additional same-age sibling. Thus the odds of disease in a child with one same-age sibling was $1 \cdot 3$, and for a child with three same-age siblings it was $1.9(p=0.01)$. Among households with numerous children there were no differences in rates of active trachoma for those with fewer sleeping rooms than those with numerous sleeping rooms.

Independently of the number of children in the household the presence of trachoma in school-age siblings aged 6-14 was associated with inflammatory trachoma in children aged 1-5. The prevalence of trachoma in preschool children in the 15 households that had no schoolage sibling was $36 \%$, the same as the prevalence in the 54 households with non-trachomatous school-age siblings (37\%). By comparison there was a high prevalence (78\%) of trachoma in preschool children in the 25 households with a trachomatous school-age sibling. Nevertheless, only $50 \%$ of diseased children had a trachomatous school-age sibling. This suggests that trachoma is more probably transmitted between younger children than from school-age youths to their younger siblings.

\section{Discussion}

Trachoma remains a serious public health problem among rural inhabitants in the Egyptian Nile Delta. The high correlation between trachoma status of children in the same household probably reflects both the infectious nature of trachoma and the strong dependence of intensity of inflammatory disease on environmental and socio-demographic factors common to the household. Thus the detection of household clustering of trachoma is fundamental in trying to explain trachoma distribution in a population and in understanding the risk factors for disease.

From a public health standpoint the reduction in the number of young children in the household is not a realistic measure. While there is a nationwide family planning programme in Egypt, a number of factors have limited the effectiveness and use of family planning in rural hamlets. Child spacing is rarely practised, and contraceptives are not used. Consequently, women bear children throughout their childbearing years. In the recent past maternal and child care has improved, with the result that infant mortality is only $85 / 1000$ live births and life expectancy at birth is about 60 years. ${ }^{33}$ Because of increased child survival, households in Kafr were larger in 1987 (median = 8) than in 1972 (median $=6$ ). On the other hand new houses are continually under construction in the hamlet, and single-family dwellings are becoming more common than extended-family dwellings. Effective population control is likely to reduce the amount of trachoma as well as other infectious diseases endemic to this region.

At first glance it may appear that the identification of trachomatous school children is a simple alternative to population based surveys to identify trachoma in preschool children or trachomatous households. However, this technique is not sensitive enough to identify these preschool children; only $50 \%$ of diseased children are in households with a trachomatous schoolage sibling, and not all children attend school.

Latrines in many rural Nile Delta hamlets consist of an unscreened pit, commonly dug 10 to 15 years ago, in one of the rooms of the house. Although families with latrines do not always use them consistently, they still provide a more hygienic situation than the alternative, which is defecation in the common room used as both the kitchen and stable of the house. Small children defecate wherever it suits them inside and outside the house. Faecal matter around the house probably contributes to increased fly density. Fly suppression through application of insecticide has not yielded good enough results to recommend it as a long-term preventive measure of trachoma. ${ }^{34}$ Fly control, which may be partially achieved through the introduction of screened pit latrines, has been suggested previously, though controlled studies have not been undertaken and the cost and efficacy of achieving it are not clear. ${ }^{2035}$ Nevertheless in the Egyptian setting the presence of pit latrines in all houses, even when full and unscreened, might result in a reduction in trachoma prevalence in this population from the current $49 \%$ to $35 \%$. The construction of latrines should be encouraged to improve general hygiene and reduce trachoma in this region.

The authors thank Drs M E Said, M Sadek, B Mihkail, A Reizian, Mr M Hanna for their substantial assistance in this study. The authors also thank the residents of Kafr for the co-operation. The project was supported in part by grants from the Edna McConnell project was supported in part by grants from the Edna McConnell 02162, EY 07058, and PL 480 03-024.
02162

1 Tielsch JM, West KP, Katz J, et al. The epidemiology of trachoma in southern Malawi. Am F Trop Med Hyg 1988; 32: trachor.

2 Sowa S, Sowa J, Collier LH, Blyth A. Trachoma and allied infections in a Gambian village. London: Medical Research Council, 1965.

3 Taylor HR, Velasco FM, Sommer A. The ecology of trachoma: an epidemiological study in southern Mexico. Bull WHO 1985; 63: 559-67.

4 Foster SO. Trachoma in an American Indian village. Public Health Rep 1965; 80: 827-32.

5 Portnoy GL, Portnoy SB. Epidemiology of trachoma in the San Xavier Papago Indians. Arch Opthalmol 1971; 86: 260-2.

6 Mathur GM, Sharma R. Prevalence of trachoma and other common eye diseases. Ind 7 Med Res $1970 ; 58: 1085-99$.

Royal Australian College of Ophthalmologists. The National Trachoma and Eye Health Programme of the Royal Australian Trachoma and Eye Health Programme of the

8 Lane SD. A biocultural study of trachoma in an Egyptian hamlet. PhD dissertation. San Francisco: University of California, 1987.

9 Parthasarathy NR, Gupta CK. Influence of some of the socioeconomic factors in the prevalence of trachoma. Ind $\mathcal{F}$ Social Work 1962; 23: 127-31.

10 Taylor CE, Gulati PV, Harinarain J. Eye infections in a Punjab village. Am f Trop Med Hyg 1958; 7: 42-50.

11 Brilliant LB, Pokheral RP, Grasset NC, et al. Epidemiology of blindness in Nepal. Bull WHO 1985; 63: 375-86.

12 Gilbert SS. Trachoma in Nepal: an investigation into sociocultural and individual factors. $\mathrm{PhD}$ dissertation. Ann Arbor: University of Michigan, 1983.

13 Winkler PF. The morbidity survey on trachoma and other communicable eye diseases in the district of Hebron, Jordan, 1960. Bull WHO 1963; 28: 417-36. 
14 Marshall CL. The relationship between trachoma and piped water in a developing area. Arch Environ Health 1968; 17: 215-20.

15 Amies CR, Loewenthal LJA, Murray NL, Scott JG. Blindness in the Bantu: a survey of external eye disease and malnutrition in the Bantu: a survey of external eye disease and malnutrition

16 Kok PW. The epidemiology of trachoma blindness in Southern Africa. Soc Sci Med 1983; 17: 1709-13.

17 Pratt-Johnson JA, Wessels JHW. Investigation into the control of trachoma in Sedkhukuniland. S Afr Med F 1958; 32: 2125.

18 Taylor HR, West SK, Mmbaga BBO, et al. Hygiene factors and increased risk of trachoma in Central Tanzania. Arch Ophthalmol 1989; 107: 1821-5.

19 de Sole G. Impact of cattle on the prevalence and severity of trachoma. Brf Ophthalmol 1987; 71: 873-6.

20 Jones BR, Darougar S, Mohsenine H, Poirier RH. Communicable ophthalmia: a blinding scourge of the Middle municable ophthalmia: a blinding sco

21 Cooper SN. Trachoma: a bio-meteorological approach. $f$ AllIndia Ophthalmol Sac 1964;12:50-8.

22 Dhir SP, Detels R, Alexander ER. The role of environmental factors in cataract, pterygium and trachoma. Am $\mathcal{J}$ Ophthalmol 1967; 64: 128-35.

23 Bobb AA, Nichols RL. Influence of environment in clinical trachoma in Saudi Arabia. Am 7 Ophthalmol 1969; 67: 23543.

24 Nichols RL, Von Fritzinger K, McComb DE. Epidemiological data derived from immunotyping of 338 trachoma strains Trachoma and related disorders caused by chlamydial agents Trachoma and related disorders caused by chlamydial agents Ex.
25 Assaad FA, Maxwell-Lyons F, Sundarsen T. Use of local variations in trachoma endemicity in depicting interplay between socio-economic conditions and disease. Bull WHO 1969; 41: 181-94.

26 Courtright P, Sheppard J, Schachter J, Said ME, Dawson CR. Trachoma and blindness in the Nile Delta: current patterns and projections for the future in the rural Egyptian populaand projections for the future in the rural

tion. Br f Ophthalmol 1989; 73: 535-40.
27 Said ME, Goldstein H, Korra A, El-kashlani K. Prevalence and causes of blindness in urban and rural areas of Egypt. Public Health Rep 1970; 85: 587-99.

28 Barsoum IS, Mostafa MSE, Shihab AA, El-Alamy M, Habib MA, Colley DG. Prevalence of trachoma in school children and ophthalmological outpatients in rural Egypt. Am f Trop Med Hyg 1987; 36: 97-101.

29 Said ME, Goldstein H, Korra A, El-kashlani K. Distribution of visual acuity in Egypt. Health Serv Rep 1974; 89: 247-55.

30 Dawson CR, Jones BR, Tarrizo ML. Guide to trachoma control. Geneva: World Health Organisation, 1981.

31 EGRET. Statistics and Epidemiology Research Corporation, 909 NE 43rd Street, Seattle, WA 98105, USA.

32 Courtright $\mathrm{P}$. Household clustering of trachoma and its role in the analysis of risk factors. Dr PH dissertation. Berkeley: University of California, 1988.

33 World Bank. World Development Report 1989. Washington, DC: World Bank, 1989.

34 Reinhards J, Weber A, Nizetic B, Kupka K, MaxwellLyons $F$. Studies in the epidemiology and control of seasonal conjunctivitis and trachoma in southern Morocco. Bull WHO 1965; 39: 497-545.

35 Jones BR. The prevention of blindness from trachoma. Trans Ophthalmol Soc UK 1975; 95: 16-32. 